\section{Seguimos avanzando}

\author{
We keep moving ahead
}

\section{Manuel Antonio Mattos-Vela ${ }^{1, a, b}$, Luis Cuadrao Zavaleta ${ }^{1, a, c}$}

\author{
1 Facultad de Odontología. Universidad Nacio- \\ nal Mayor de San Marcos. Lima, Perú. \\ a Doctor en Estomatología \\ b Editor general de la Revista Odontología San- \\ marquina \\ c Director de la Revista Odontología Sanmarquina
}

Correspondencia:

Manuel Antonio Mattos-Vela

Correo electrónico: mmattosv@unmsm.edu.pe

Facultad de Odontología, UNMSM. Calle

Germán Amézaga 375. Lima 1, Perú.

Coautor:

Luis Cuadrao Zavaleta

lcuadraoz@unmsm.edu.pe

Fecha de recepción: 22/06/17

Fecha de aceptación: 29/06/17
¿Cómo inspirarnos y motivarnos para el trabajo que realizamos? Abrazando una visión. Teniendo claro dónde queremos llegar.

La Revista de Odontología Sanmarquina (ROS) tiene ya varias décadas de existencia con la misión de difundir conocimiento científico de calidad en el campo de la odontología, a la profesión y a la sociedad. Desde el mes de abril de este año, la revista cuenta con un nuevo Equipo Editor, que toma la posta de la gestión del proceso editorial.

¿Cuál es la situación de las revistas odontológicas peruanas? Son pocas y sólo una está indizada en la base de datos SciELO, que es una base de datos regional; ninguna está en bases de datos de nivel mundial, como MEDLINE, ScienceDirect o SCOPUS. Esto, debido a los altos estándares requeridos para ingresar a estas bases de datos, los cuales son necesarios para asegurar calidad de las publicaciones científicas ${ }^{1-4}$, sin embargo, estos criterios son alcanzables, teniendo una visión clara, aplicando estrategias adecuadas y trabajando arduamente.

Este nuevo equipo busca seguir avanzando en las mejoras de calidad de la revista, para ello, se han tomado las siguientes medidas. Aplicar un sistema de revisión por pares a doble ciego (ni los autores, ni los revisores conocen la identidad del otro). Establecer un Comité Consultivo diverso (de distintas nacionalidades y especialidades) integrado por 18 investigadores de experiencia que puedan asesorar al Comité Editor (integrado por docentes de la Facultad de Odontología) en las políticas y proceso editorial de la revista. Establecer plazos para cada una de las etapas del proceso editorial de los artículos (todo el proceso de revisión durará como máximo cuatro meses), atendiendo oportunamente las consultas realiza- das por los autores o revisores. Aplicar a todos los manuscritos recibidos un software antiplagio (TURNITIN) para verificar su originalidad, además, desde el 2017 la Revista sólo tendrá versión electrónica. Todo esto, ya se está realizando desde este año, siendo las dos últimas medidas, dispuestas por el Vicerrectorado de Investigación y Posgrado para todas las Revistas científicas de la Universidad Nacional Mayor de San Marcos.

Hay metas que el Equipo Editor de la ROS pretende alcanzar para los próximos meses o años. Indizar la Revista en bases de datos regionales e internacionales: LILACS (Literatura Latinoamericana en Ciencias de la Salud), SciELO (Scientific Electronic Library Online) y SCOPUS, así como, registrar la Revista en DOAJ (Directory of Open Access Journal), lo cual permitirá elevar su visibilidad. A partir del 2018, la Revista emitirá tres números por año, así, los 
autores cuyos manuscritos hayan pasado todo el proceso de revisión editorial podrán ver prontamente su artículo publicado. Además, con la finalidad de hacer llegar a la población los conocimientos científicos relevantes y de interés público, se enviarán notas de prensa a los medios de comunicación escrito, radial y televisivo, en lenguaje sencillo, informando los resultados de las investigaciones publicadas en la ROS, que así lo ameriten.

La tarea que se tiene por delante no es sencilla, el Equipo Editor es consciente de las limitaciones que le acompañan (de recursos financieros, de personal, de tiempo y administrativos), sin embargo, tiene esperanza y se enfoca en las fortalezas que posee. La principal de ellas: contar con un grupo humano renovado, con visión, capaz y comprometido con la tarea asumida. Convocamos a la comunidad odontológica latinoamericana a apoyar este esfuerzo; a los autores, que presentan sus manuscritos a la ROS, a los revisores, que colaboran en la calidad de los artículos publicados, a los lectores, que nos preferencian con su atención y al cuerpo editorial, que trabaja para ofrecer una revista con información científica útil a la profesión. ¡Juntos podemos!

\section{Referencias bibliográficas}

1. US National Library of Medicine [Internet]. Maryland: FAQ: MEDLINE Indexing Requirements for electronic Journals [actualizado 21 Mar 2017; citado 13 Jun 2017]. Disponible en: https://www.nlm. nih.gov/services/ejournals.html
2. Elsevier [Internet]. Amsterdam: Scopus [actualizado 2017; citado 13 Jun 2017]. Disponible en: https://www.elsevier.com/solutions/scopus

3. Castrillón-Estrada JA, García JC, Anaya M, Rodríguez D, de la Rosa D, Caballero-Uribe CV. Bases de datos, motores de búsqueda e índices temáticos: herramientas fundamentales para el ejercicio médico. Salud Uninorte. 2008;24(1):95119.

4. Miguel S. Revistas y producción científica de América Latina y el Caribe: su visibilidad en SciELO, RedALyC y SCOPUS. Rev Interam Bibliot. 2011;34(2):187-199. 